\title{
On the Development of the Aspect System in Some Philippine Languages
}

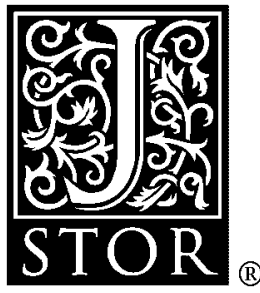

\author{
Lawrence A. Reid
}

Oceanic Linguistics, Vol. 31, No. 1. (Summer, 1992), pp. 65-91.

Stable URL:

http://links.jstor.org/sici?sici=0029-8115\%28199222\%2931\%3A1\%3C65\%3AOTDOTA\%3E2.0.CO\%3B2-J

Oceanic Linguistics is currently published by University of Hawai'i Press.

Your use of the JSTOR archive indicates your acceptance of JSTOR's Terms and Conditions of Use, available at

http://www.jstor.org/about/terms.html. JSTOR's Terms and Conditions of Use provides, in part, that unless you have obtained prior permission, you may not download an entire issue of a journal or multiple copies of articles, and you may use content in the JSTOR archive only for your personal, non-commercial use.

Please contact the publisher regarding any further use of this work. Publisher contact information may be obtained at http://www.jstor.org/journals/uhp.html.

Each copy of any part of a JSTOR transmission must contain the same copyright notice that appears on the screen or printed page of such transmission.

The JSTOR Archive is a trusted digital repository providing for long-term preservation and access to leading academic journals and scholarly literature from around the world. The Archive is supported by libraries, scholarly societies, publishers, and foundations. It is an initiative of JSTOR, a not-for-profit organization with a mission to help the scholarly community take advantage of advances in technology. For more information regarding JSTOR, please contact support@jstor.org. 


\title{
ON THE DEVELOPMENT OF THE ASPECT SYSTEM IN SOME PHILIPPINE LANGUAGES ${ }^{1}$
}

\author{
LAWRENCE A. REID
}

UNIVERSITY OF HAWAII

The verbal morphology of Philippine languages, typically complex, usually includes distinctions of voice, mode, and aspect that are problematic with respect to whether they are inflectional or derivational. This paper attempts to give an account of the development of the aspect systems of Tagalog and Ilokano. Their voice systems, closely intertwined with the aspect systems, are also considered. The aspect system posited for ProtoExtra Formosan closely resembles that of Ilokano. The Ilokano system resulted from a switch in the order of the two infixes $\langle u m\rangle$ and $\langle$ in $\rangle$, whereby the $\langle$ in $\rangle$ completive aspect infix came to precede rather than follow the $\langle\mathrm{um}\rangle$ focus marker, and from consequent phonological changes. The development of the Tagalog system, typical of the Central Philippine languages, was considerably more complex, involving a series of phonological changes that in turn set the stage for a series of restructurings, all of which are retraced in detail in the paper.

1. INTRODUCTION. Numerous descriptions of the verbal morphology of Philippine languages exist in the literature, frequently drawing attention to the considerable complexity of these systems. ${ }^{2}$ In addition to a wide range of forms that are clearly derivational, there are typically three sets of formal distinctions that affect almost every verb and are problematic with respect to whether they are inflectional or derivational: those marking voice (sometimes called focus), mode (sometimes called mood), and aspect. $^{3}$ The voice distinctions are given this label because they have typically been analyzed as signaling the case relation of the subject. ${ }^{4}$ The modes that are distinguished include indicative (or general), potential (or abilitative), and imperative (dependent, or irrealis), while the aspects mark the verb for features of frequency, duration, completion, and so forth. ${ }^{5}$

A comparison of these systems in Tagalog and Ilokano shows that Tagalog has a morphologically simpler voice system than Ilokano, but it has a considerably more complex aspect system. ${ }^{6}$ The purpose of this 
paper is to provide an account of the development of the aspect systems in these two languages. Modal affixation will not enter into the discussion. All forms are cited in the indicative or general mode of the languages being compared. However, because the voice and aspect systems are closely intertwined, especially in Tagalog, it is necessary to include some discussion of the voice systems as well. Although Ilokano is seen as having maintained, with relatively few changes, a system that is reconstructible to Proto-Extra Formosan, ${ }^{7}$ Tagalog is shown as having undergone considerable restructuring of its system. The main cause of this complexity is found in a single phonological change that appears to have taken place at some time early in the development of the Central Philippine languages, the subgroup of which Tagalog is a member (Zorc 1977).

2. THE TAGALOG SYSTEM. Finite verbs in Tagalog generally have three forms marking aspect; these forms are described by Schachter and Otanes (1972) as contemplated, imperfective, and perfective. ${ }^{8}$ There is, in addition, a set of non-finite forms, unmarked for aspect. De Guzman (1978:140-144) uses the features finite [fin], begun [beg] and completed [comp] (adopted from Otanes 1966:54, 1970:36-37) to capture the relevant categories.

Table 1 (De Guzman 1978, slightly modified) illustrates the intersection

TABLE 1. TAGAlOG ASPECT PARADIGMS

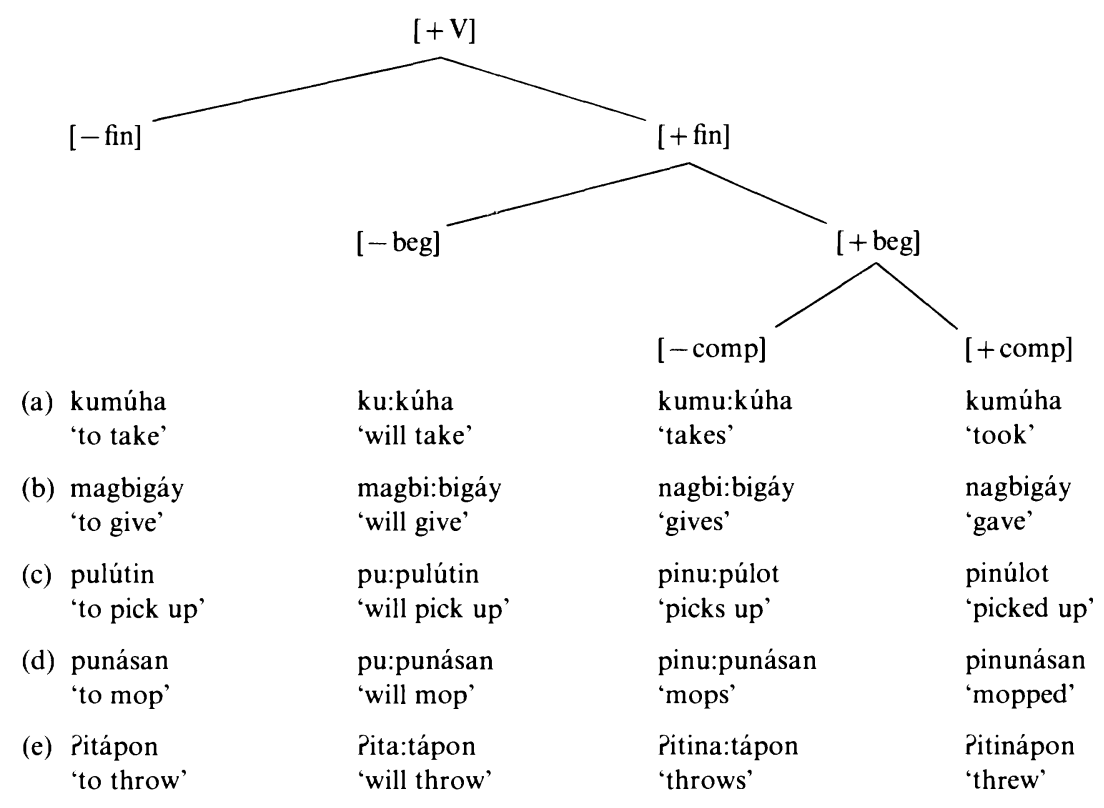


of the aspect categories in Tagalog with voice affixation. The forms in rows (a) and (b) are marked for agentive voice, while those in rows (c) through (e) are marked for one of the non-agentive voices, namely, objective (c), locative (d), and instrumental (e). ${ }^{9}$ The nonfinite verb forms in the first column are usually considered to be the basic forms. They consist of a root form with a single voice-marking affix. In row (a), the infix $\langle u m\rangle$, a reflex of Proto-Extra Formosan (PEF) * $\langle$ um $\rangle$, precedes the first vowel of the root. In row (b), the prefix mag-, a reflex of PEF *maR-, is attached to the root. ${ }^{10}$ In row (c), the suffix -in, a reflex of PEF ${ }^{*}$-en, is attached to the root in the nonfinite $[-$ fin] and future $[-$ beg] form. In row (d), the prefix $i-$, a reflex of PEF ${ }^{*}$ ?iSi-, is attached to the root. ${ }^{11}$

The forms in columns 2 and 3 all show a root reduplication of the form CV:-. Vowel length on this increment is not normally written, but is invariably present, regardless of whether or not the first root vowel carries length. Thus kumukuha is pronounced [kumu:ku:ha], with vowel length on the first root vowel, whereas magbibigay is pronounced [magbi:bigay] with no vowel length on the first root vowel.

Forms in rows (c) through (e) of columns 3 and 4, the perfective [ + comp] and imperfective [-comp] non-agentive voice forms, all show an infix $\langle$ in $\rangle$, a reflex of $\mathrm{PEF}^{*}\langle$ in $\rangle$, while the corresponding forms in row (b) show nag-, a reflex of PEF *minaR-, that is *maR- $+{ }^{*}\langle$ in $\rangle$ (Reid 1987:47-48), with loss of the first two segments of the (infixed) prefix. Row (a) appears irregular in several ways. First, neither of the 'nonfuture' $[+$ beg] forms shows any reflex of the * $\langle$ in $\rangle$ affix, with the result that the nonfinite $[-$ fin] and the perfective forms [+ comp] are identical; secondly, the 'future' [ - beg] form carries no voice affix.

The aspect system is considered by some to be inflectional, in that there is a clearly definable set of forms that commute with each other in a paradigm within which most verbs can appear. It is also productive, affecting, for example, newly borrowed forms from English such as magbasketbol 'to play basketball', and so on.

The voice system on the other hand has been treated by some as inflectional (De Guzman 1978, 1991) and by others as derivational (Bender 1988, Starosta 1986, 1988). The system seems to be inflectional in that all verbs typically carry one of the voice affixes, whose form and meaning is generally predictable based on the semantic features of the verb root, and whose occurrence can be linked to syntactic features in the case frame of the verb. The system is viewed by others as derivational because probably no verb may take the complete set of voice affixes; that is, they do not freely commute within a paradigm. The choice of one affix rather than another usually marks a semantic distinction between the forms, and this meaning change is not always predictable $;^{12}$ and the agentive affixes derive intransitive verbs, ${ }^{13}$ while the non-agentive affixes always derive transitive 
verbs. Traditionally, inflectional affixes do not carry over in derivation, but each of the voice affixes occurs as a noun-deriving affix, in addition to its verbal functions. Furthermore, the disparate nature of the set, with one infix, two suffixes, and several prefixes suggests derivation (or at least a derivational origin) rather than inflection.

Since derivational processes are by definition word-forming, that is, they create new lexical entries that are potentially inflectable, the relative order of affix application in Tagalog would seem to require that, for Tagalog at least, aspect and voice must be either both derivational, or both inflectional. With a form such as Pitinápon, it is possible to claim that it is first derived for voice (Pi-tápon 'to throw X'), and then inflected for completed aspect ("insert $\langle i n\rangle$ before the first vowel of the root" $P i-t\langle$ in $\rangle$ ápon 'threw $\mathrm{X}$ '). It is also possible to claim that with a form such as Pitina:tápon, it is first derived for voice (as above) and then inflected, first by reduplication ("reduplicate the first two segments of the root, and lengthen a short reduplicated vowel"): Pi-ta:tápon, and then by $\langle i n\rangle$ infixation: $i-t\langle$ in $\rangle$ a:tápon 'throws $\mathrm{X}$ '. However these rules cannot be applied in parallel fashion to produce a form such as kumu:kúha 'takes'. Derivation for voice ("insert $\langle u m\rangle$ before the first vowel of the stem") would produce the form kumúha, reduplication would then result in the ungrammatical ${ }^{*} k u k u m u h a .{ }^{14}$ It appears that the root must first be reduplicated before $\langle u m\rangle$ is infixed. In other words, what has been characterized as inflection must take place prior to derivation. ${ }^{15}$ An alternate analysis, and one that is used below in discussing the development of the Tagalog aspect system, treats the language as having two $\langle u m\rangle$ infixes. The first, $\left\langle u m_{1}\right\rangle$, occurs in the nonfinite form, $k\left\langle u m_{1}\right\rangle u$ u $a$ 'to get'. The second, $\left\langle u m_{2}\right\rangle$, occurs in the [+beg] forms, $k\left\langle u m_{2}\right\rangle$ úha 'got' and $k\left\langle u m_{2}\right\rangle u$ :kúha 'getting'. In these forms it is an allomorph of $\langle i n\rangle$.

A related problem occurs with a form such as pinulot. The voice affix on this form is absent, although it is present on forms in the same paradigm that do not have an $\langle$ in $\rangle$ infix. This has been treated as a case of haplology (Bender 1988). However, there is no Philippine language in which these two affixes co-occur, even though the vowel of the suffix is reflected differently from that of the infix in some languages. They act as though they belong to the same inflectional paradigm. Historically, though, it is apparent that the completive aspect affix $\langle$ in $\rangle$ and the objective voice affix -in were derivational alternatives. The former was a derivational affix * $\langle$ in $\rangle$ that derived nouns that were the result of the action of the verb, as in Tagalog $b\langle$ in $\rangle$ ili 'something that was bought' (bili 'buy'). The latter was a derivational affix ${ }^{*}$-en that derived nouns that would receive the action of the verb, as in bilihin 'something to be bought'. They could not co-occur (Starosta, Pawley, and Reid 1982:162-163). 
TABLE 2. ILOKANO ASPECT PARADIGMS

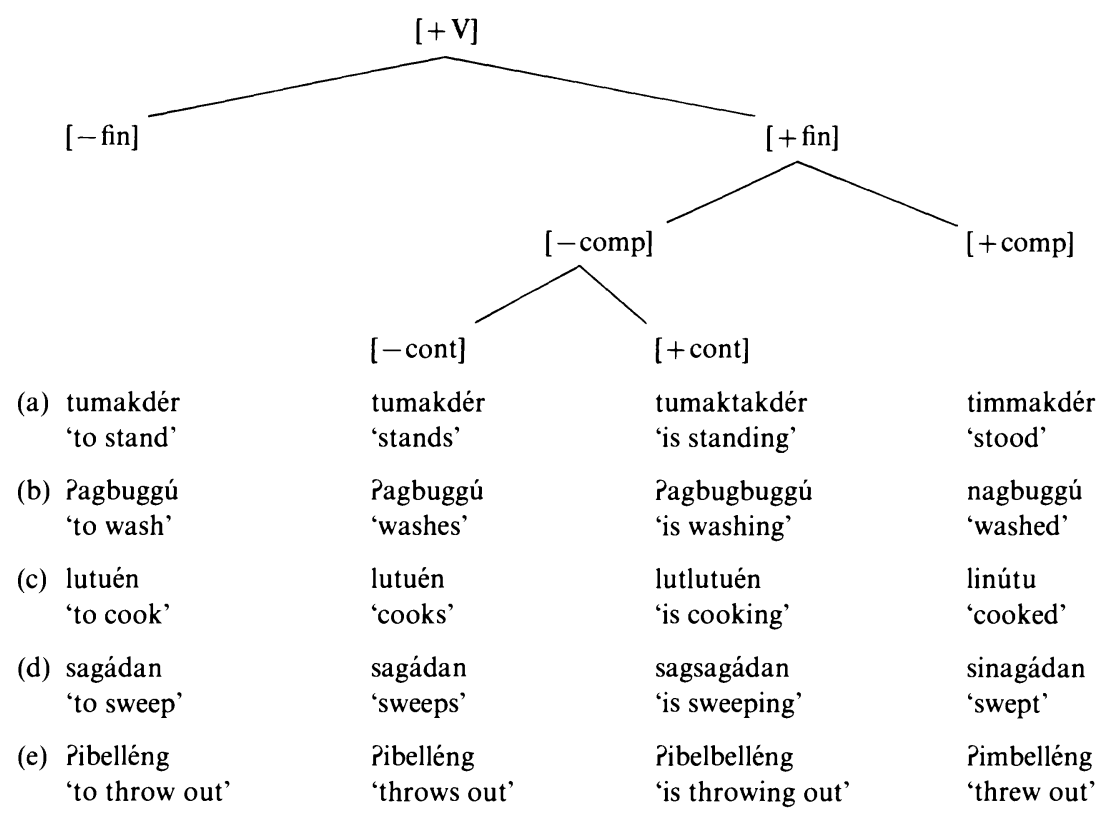

3. THE ILOKANO SYSTEM. Ilokano verbs, like those of Tagalog, can be described as having three aspect forms. However, there is little systematic correspondence between the two languages. Only one of the features that define the Tagalog system can be used for Ilokano. In Ilokano, all verbs are either completive or not [ \pm comp]. Completive verbs typically have past time reference and are perfective. Noncompletive verbs are typically used with either present or future time reference, although they may readily occur with past reference as well (examples 4 and 5 below.) They may be either continuative or not $[ \pm$ cont $]$. Continuative verb forms are imperfective. In Ilokano, there is no distinct nonfinite verb form. The basic form, that is, the one that occurs only with a voice affix, is marked in the same way as the noncontinuative, noncompletive verb form. The continuative [ + cont] form is marked by reduplication of the first three segments of the root, CVC-, with the general sense of 'distributed referent'. Completive verbs are marked with the infix $\langle$ in $\rangle$.

Table 2 illustrates the intersection of the Ilokano aspect categories with voice affixation. ${ }^{16}$ As in Table 1, the forms in rows (a) and (b) are affixed for agentive voice, while those in rows (c) through (e) are affixed for one of the non-agentive voices: objective (c), locative (d), and instrumental (e). In row (a), the infix $\langle u m\rangle$ (or one of its variants) precedes the first vowel 
of the root. In row (b), the prefix Pag-, a probable development of PEF ${ }^{*} \mathrm{maR}$-, is attached to the root. In rows (c) and (d), the suffixes -en and -an are attached to the root in the noncompletive [-comp] forms. In row (e), the prefix $P i$ - is attached to the root. The completive infix $\langle i n\rangle$ combines with $P i$ - as in-(Pi- $+\langle$ in $\rangle \rightarrow$ Pini- $\rightarrow$ Pin-). In other words, the voice affix is attached to the verb first, with the infix being inserted into it. The same sequence is apparent in row (a). The form $t\langle i m m\rangle$ akder is the result of first infixing the voice affix $\langle u m\rangle$ and then inserting $\langle$ in $\rangle$, with subsequent vowel deletion and nasal assimilation ( $\langle$ inum $\rangle \rightarrow\langle$ inm $\rangle \rightarrow\langle$ imm $\rangle)$.

Although CVC-reduplication may also co-occur with verbs that have an $\langle$ in $\rangle$ infix and are sometimes translated as past imperfective, ${ }^{17}$ they do not carry an imperfective sense, but are either repetitive (example 1), or distributive (example 2), depending on the verb stem, and the context. The action is always understood as completed. Compare example 3 (completed, distributive), with 4 and 5 (noncompletive, continuative). In a negative construction, CVC-reduplication with an $\langle$ in $\rangle$ affix is interpreted as 'ever, at any time, at all', as in example $6 .{ }^{18}$

1. Immin-inum diay aso. $\langle$ in $\rangle\langle$ um $\rangle$ CVC-drink DET dog. 'The dog drank and drank.'

2. Gimmatgatangda ti sapatos. $\langle$ in $\rangle\langle$ um $\rangle$ CVC-buy-they DET shoes 'They kept on buying shoes.'

3. Nagbasbasaak ti libro. $\langle$ in >ag-CVC-read-I DET book 'I kept on reading a book (or books).'

4. Agbasbasaak ti libro. ag-CVC-read-I DET book 'I am reading a book.'

5. Agbasbasaak ti libro idi simrekda. ag-CVC-read-I DET book when $\langle$ in $\rangle\langle$ um $\rangle$ enter-they 'I was reading a book when they entered.'

6. Saanak a gimmatgatang ti sapatos. not-I LIG $\langle$ in $\rangle\langle$ um $\rangle$ CVC-buy DET shoes 'I never bought any shoes.'

The CVC-reduplicative pattern occurs with various other functions in Ilokano, including pluralization of some nouns, and the comparative degree of adjectives. Since the number of nouns that can be pluralized in this way is highly restricted, reduplication here is clearly not to be interpreted as an inflectional category, but rather as a special instance of 
the more general pattern described above meaning 'distributed referent'. There are also other reduplicative patterns. One is $\mathrm{CV}$-, which derives words that interpret their patients as distributed in time and/or space. It optionally occurs on ag-derived verbs whose subjects are plural. Another reduplicative pattern is $\mathrm{CV}(\mathrm{C}) \mathrm{CV}(\mathrm{C})$ - (i.e., all of a disyllabic root); it derives forms that express multiply repetitive action.

One other fact about Ilokano reduplication needs to be mentioned here. The CVC-pattern (regardless of its function) has a variant containing a long vowel, CV:-, occurring with roots that have a medial glottal stop, regardless of the stress pattern of the root, as in examples 7 and 8 (intervocalic glottal stop is not written in standard Ilokano orthography). This can be seen as resulting from a phonotactic constraint that does not permit consonant clusters with initial glottal stop. Vowel length occurs instead of glottal stop in the pattern.

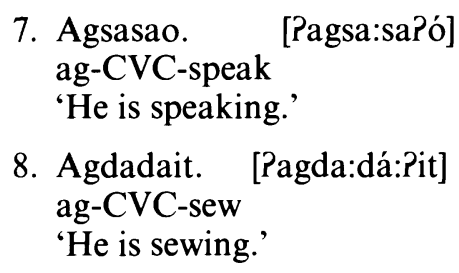

4. PROTO-EXTRA FORMOSAN ASPECT. In order to account for the development of the two systems characterized above, an attempt must be made to reconstruct an aspect system for their immediate protolanguage. In order to do this, several questions need to be answered. They include the following. (1) Was PEF more like Ilokano in having a completed/noncompleted feature set, or like Tagalog, with a begun/ nonbegun set? (2) Was PEF more like Ilokano in requiring voice affixation before infixation of $\langle$ in $\rangle$, or like Tagalog in which $\langle$ in $\rangle$ appears to be infixed before voice affixation? (3) What was the form of the 'distributed referent' reduplicative pattern that marked continuative verb forms in PEF?

4.1 An examination of the aspect systems of Philippine languages from various subgroups suggests that PEF was probably more like Ilokano in having a distinction between completed and noncompleted verb forms, with the former marked by the infix $\langle$ in $\rangle$, than like Tagalog, in which $\langle$ in $\rangle$ marks an action that has begun, as against one that is still in the future.

In Ivatan, in the far north of the Philippines, Hidalgo and Hidalgo $(1971: 53,70)$ describe tense as either past or nonpast, with past tense 
marked with a reflex of $*\langle$ in $\rangle$. Subject focus (i.e., agentive voice) verbs, which use reduplication to mark repetitive action, have $m$-initial forms, not $n$-initial forms as do the Tagalog equivalents.

9. Ivatan (Hidalgo and Hidalgo 1971:72)

mayvayvahay 'building a house'

manutunutung 'cooking'

tumatada 'dancing repeatedly'

Sambalic languages similarly restrict the use of $*\langle$ in $\rangle$ reflexes to perfective forms.

10. Kapampangan (Gonzalez 1972:30)

murán 'it will rain'

múmurán 'it is raining'

minurán 'it has rained'

11. Botolan Sambal (Antworth 1979:26-27)

itanem 'to plant $\mathrm{x}$ (contemplated)'

an-itanem 'to plant $x$ (imperfective)'

intanem 'to plant $x$ (perfective)'

All Cordilleran languages are like Ilokano in restricting the use of * $\langle$ in $\rangle$ reflexes to perfective forms.

12. Ibanag (Brandes and Scheerer 1927-28:20): "in the formation of the perfect, -in- is added to infix -um-."

lumáka? 'walks'

limináka? 'walked'

umulú? 'descends'

minulú? 'descended'

13. Balangaw (Shetler 1976:78): "Tense ... is either past or nonpast. Nonpast tense is indicated by $m-\ldots$. Past tense is marked by addition of -in- or simply $n$-"

mansoblak-ayu 'you wash'

nansoblak-ayu 'you washed'

tombala 'I will answer'

tenumbala 'I answered' 
14. Pangasinan (Benton 1971:123): "Tense is determined by means of a formal contrast between a pair of affixes ... that can be described as 'past' and 'non-past' ... on- (actual, incomplete), -inm- (actual, complete)"
oninóm '(he) will drink'
oniinóm '(he) is drinking'
inminóm '(he) was drinking, (he) drank'
onbatik 'he will run'
onbabatík 'he is running'
bínmatík 'he ran'

Manobo languages in Mindanao likewise use reflexes of * $\langle$ in $\rangle$ only in perfective verb forms. ${ }^{19}$

15. Ilianen Manobo (Shand 1964:54): "The markers for tense are ed- 'non-past tense', mid- 'past tense', and med- 'unreal tense."

edtibas

'will slash'

midtibas 'slashed'

wara' medtibas 'did not slash'

16. Ata Manobo (Morey 1964:71): “The ... morpheme og-means that the action expressed by the verb is incomplete. Whether that action has begun or has not begun is irrelevant.... The meaning of the aspect nig- is 'complete'; the action has been completed or is no longer happening.... The 'unreal' aspect, marked by $m$-, expresses the unreality of an action"

$\begin{array}{ll}\text { qogqogot } & \text { 'scolds, will scold' } \\ \text { nigqogot } & \text { 'scolded' } \\ \text { qogot }^{20} & \text { 'scold' }\end{array}$

The Danao languages of Mindanao likewise use reflexes of * $\langle$ in $\rangle$ only in perfective verb forms.

17. Maranao (McKaughan 1958: 28): "There are four tenses: neutral, past, immediate future, and present progressive.... The past tense is marked by the infix $-i-$, and indicates that the action has been completed."
tabasan 'slash'
tiabasan 'slashed'
tebasan 'will slash'
petebasan 'is slashing' 
18. Agutaynen of Northern Palawan (Quakenbush, pers. comm.), possibly an isolate in the Philippine language family (Blust 1991), restricts the infix $\langle$ in $\rangle$ to completive forms. It, like other languages of Palawan (see note 21), shows influence from Tagalog in that it distinguishes future from present. Quakenbush suggests that the tense-aspect system in Agutaynen is structured as shown in Table 3.

The only languages that are like Tagalog in using 〈in〉 to mark a distinction between begun and not-begun verb forms are the other languages of the Central Philippines, including Bikol, Bisayan, Mansaka, and languages such as Palawano (where Tagalog is the trade language) and possibly Kagayanen Manobo, which has been heavily influenced by one of the Bisayan languages. ${ }^{21}$ Zorc $(1977: 118-121,133-138)$ provides verb paradigms for each of the Bisayan speech varieties, including Tausug, all of which pattern like Tagalog in distinguishing "actual" $[+$ beg] from "contingent" [ - beg], and perfective [ + comp] from imperfective [-comp] forms. $^{22}$ Actual perfective aspect is used for past and perfect; actual imperfective is used to convey present, progressive, and habitual meanings. All "general mode" actual forms show a reflex of * $\langle$ in $\rangle$.

In discussing the morphological innovations that characterize the Central Philippine subroup, Zorc $(1977: 232)$ provides a reconstruction of some of the Proto-Malayo-Polynesian (PMP) verb affixation. He reconstructs PMP *nagCV- for "progressive durative active," and *magCV- for

\section{TABLE 3. AGUTAYNEN ASPECT PARADIGMS}

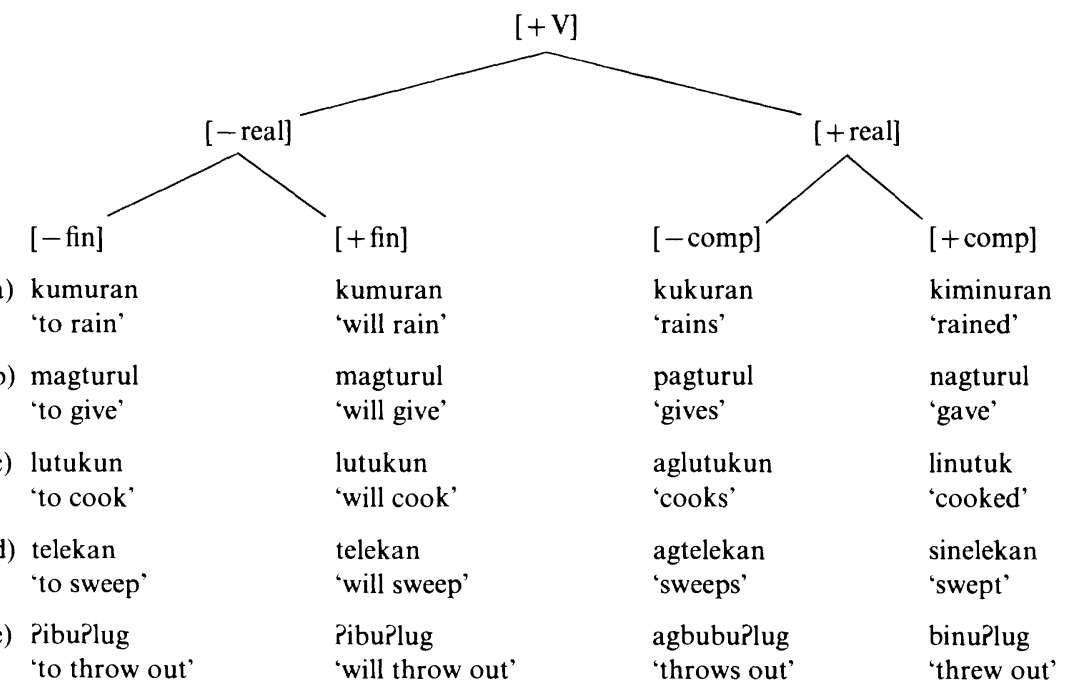


"future durative active," thereby implying that the basic aspectual distinction between begun and not-begun found in the Central Philippine languages is inherited rather than innovated. The evidence presented above, however, suggests the opposite, that is, the immediate parent language of all of the Philippine languages (PMP in Zorc's terms, PEF in mine) made a basic aspectual distinction between completed [+ comp] and noncompleted [ - comp] forms, with the former marked by * $\langle$ in $\rangle$, and that the Central Philippine languages have innovated their present systems. In fact, for a large number of Bisayan dialects distributed across the various Bisayan subgroups (as reported by Zorc 1977:130), a basic distinction between completed and noncompleted forms is still maintained in the "potential mode" of the verb forms. The innovations are typically found only in the "general mode" of the verb.

4.2 The second question that needs to be answered is whether PEF was more like Ilokano in requiring voice affixation before infixation of $\langle$ in $\rangle$, or like Tagalog in which the insertion of $\langle i n\rangle$ appears to occur prior to voice affixation.

Verbs with suffixal voice affixation tell us nothing about the relative order of affixation, since either infixation or suffixation could take place prior to the other, without any difference in the output. Verbs that are prefixed, as with $P i-$, or infixed, as with $\langle u m\rangle$, are revealing, in that if $\langle i n\rangle$ infixation takes place before voice affixation, the results are $P i-\mathrm{C}\langle i n\rangle \mathrm{V}$, and $\mathrm{C}\langle u m\rangle\langle$ in $\rangle \mathrm{V}$ - respectively, whereas if $\langle$ in $\rangle$ infixation takes place after voice affixation, the results are $P\langle$ in $\rangle i-\mathrm{CV}$, and $\mathrm{C}\langle$ in $\rangle\langle u m\rangle \mathrm{V}$ - respectively. Ilokano reflects the latter type, with earlier $*$ ? $\langle$ in $\rangle \mathrm{i}$ - becoming in- before consonant-initial stems (with nasal assimilation), but iny-before vowel-initial stems, ${ }^{23}$ as in $18 \mathrm{a}$, and with ${ }^{*}\langle$ in $\rangle\langle$ um $\rangle$ becoming $\langle$ imm $\rangle$ in stems without vowel syncopation, but $\langle i m\rangle$ in stems with vowel syncopation, as in $18 \mathrm{~b}$.

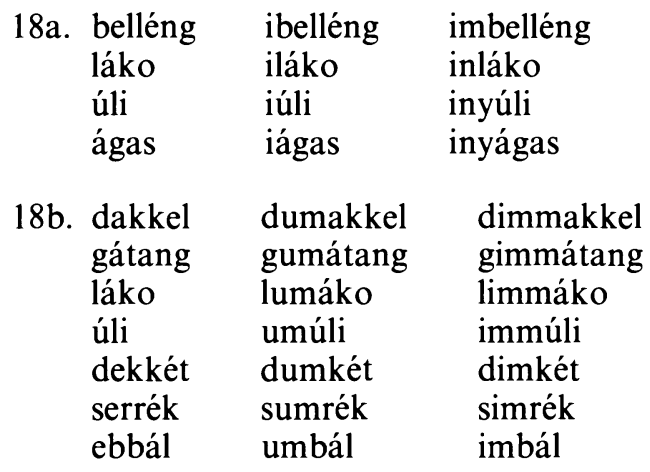


An examination of languages from each of the major subgroups in the Philippines suggests that the Tagalog order of affixation, in which $\langle$ in $\rangle$ appears to be infixed prior to the affixation of voice affixes, is historically prior to the order found in Ilokano. ${ }^{24}$ This assertion is made despite the fact that there are a number of languages in different subgroups that show $\langle$ in $\rangle$ being infixed subsequent to $\langle u m\rangle$ affixation. For example, Bolinao linmibed (from earlier $l\langle i n\rangle\langle u m\rangle$ ibed) 'went around' (but see Kapampangan minurán, example 10 above, in which the reverse order occurs), and Mansaka kyomaan (from earlier $k\langle i n\rangle\langle u m\rangle a a n$ ) 'finished eating' (Svelmoe and Svelmoe 1974:31), but mindateng 'arrived', and minlabay 'passed by' (Miller and Miller 1976:48, 50), which reflect the reverse order. Similarly Yogad ginumalit 'departed', dinumanga 'arrived, and dinumama 'walked' (Reid 1978), but Ibanag limináka? 'walked' (with vowel harmony, example 12 above) show opposite orders of affixation. Itawis imminum 'drank', and limmabbet 'returned home' (Reid 1978) could reflect the same order as Ibanag with vowel harmony and progressive nasal assimilation, or the Yogad order with regressive nasal assimilation.

Although most of the languages of the Northerm Philippines are similar to Ilokano in requiring voice affixation prior to infixation of $\langle$ in $\rangle$, a number of languages show frozen forms in which the order is reversed, and in some languages (e.g., Kalinga) the older order of affixation is retained for verbs that are affixed with $\langle u m\rangle$, while the innovated order affects only verbs that are affixed with $P i$ -

19. In Kalinga as spoken in Guinaang (Gieser 1963:18, 19, 32) $\langle u m\rangle$ is noncompleted, and $\langle u m m\rangle$ (from $\langle u m\rangle\langle i n\rangle$ ) is completed (19a), whereas $P i$ - is noncompleted, but $P$ in- (from $P\langle i n\rangle i$-) is completed (19b).

19a. dumakol dummakol tumulung tummulung

19b. Pita?od PintaPod Pibaga Pimbaga

20. In Balangaw (Shetler 1976:43) the pattern described above for $\langle u m\rangle$ verbs in Kalinga applies only to verbs in which the initial vowel is not syncopated (20a). If the vowel is syncopated, the order of affixing follows the innovated pattern of $\langle u m\rangle$ first, then $\langle$ in $\rangle$ (20b). ${ }^{25}$ Affixation of $P i$ - verbs is similar to that described for Kalinga and Ilokano, with infixation occurring following prefixation (20c).

20a. Pále Pumále Pummále

tùdu, tumùdu tummùdu 


\begin{tabular}{|c|c|c|c|}
\hline $20 \mathrm{~b}$. & $\begin{array}{l}\text { Pèdah } \\
\text { tèbal }\end{array}$ & $\begin{array}{l}\text { Pumdah } \\
\text { tombal }\end{array}$ & $\begin{array}{l}\text { Pinumdah } \\
\text { tenumbal }\end{array}$ \\
\hline 20c. & $\begin{array}{l}\text { Pale } \\
\text { baga }\end{array}$ & $\begin{array}{l}\text { Piyale } \\
\text { Pibaga }\end{array}$ & $\begin{array}{l}\text { Pinyale } \\
\text { Pimbaga }\end{array}$ \\
\hline
\end{tabular}

In a number of Northern Philippine languages, including Northern and Southern Alta, and Casiguran Dumagat (Reid 1988), affixation of the completed aspect of actor focus, pag- and pang-derived verbs, is minag-, or minang-, requiring reconstruction of Proto-Cordilleran ${ }^{*} \mathrm{~m}\langle$ in $\rangle \mathrm{aR}$ - and ${ }^{*} \mathrm{~m}\langle$ in $\rangle \mathrm{aN}-{ }^{26}$ each of which implies infixation of $*\langle$ in $\rangle$ prior to voice affixation. In numerous other languages, these forms have now been reduced to $n$-initial prefixes, such as Ilokano nag- and nang-.

In Sarangani Manobo (Du Bois n.d.:24, 47) the order of affixation for both $\langle u m\rangle$ verbs and $P i$ - verbs with $\langle i n\rangle(22 \mathrm{a}, \mathrm{b})$ is the same as that described above for Ilokano (18a, b), but for verbs with either an initial labial stop or a glottal stop, the "past tense" of $\langle u m\rangle$ verbs is min- with deletion of the initial consonant (22c).

\begin{tabular}{|c|c|c|c|}
\hline $22 \mathrm{a}$. & $\begin{array}{l}\text { dateng } \\
\text { goyod } \\
\text { kaen }\end{array}$ & $\begin{array}{l}\text { domateng } \\
\text { gomoyod } \\
\text { komaen }\end{array}$ & $\begin{array}{l}\text { dimateng } \\
\text { gimoyod } \\
\text { kimaen }\end{array}$ \\
\hline $22 b$. & $\begin{array}{l}\text { data } \\
\text { ligbin } \\
\text { agbel }\end{array}$ & $\begin{array}{l}\text { idata } \\
\text { iligbin } \\
\text { i-agbel }\end{array}$ & $\begin{array}{l}\text { indata } \\
\text { inligbin } \\
\text { in-agbel }\end{array}$ \\
\hline $22 \mathrm{c}$. & $\begin{array}{l}\text { bayad } \\
\text { panggas } \\
\text { adek }\end{array}$ & $\begin{array}{l}\text { mayad } \\
\text { manggas } \\
\text { madek }\end{array}$ & $\begin{array}{l}\text { minayad } \\
\text { minanggas } \\
\text { minadek }\end{array}$ \\
\hline
\end{tabular}

Languages that reflect the reconstructed $*\langle u m\rangle\langle$ in $\rangle$ order without change include Ivatan and Itbayaten, as in tominbay 'answered', tominwaw 'appeared' (Larson 1986:160, 165); Agutaynen and Aborlan Tagbanwa $\langle$ imin〉 (with vowel harmony), as in Agutaynen kiminuran 'rained', see Table 3); and Sorsogon 〈umin〉 (Zorc 1977:138). Zorc reconstructs * $\langle$ umin $\rangle, *\langle$ im $\rangle$, and * $\langle$ in $\rangle$ for Proto-Bisayan (1977:247).

I have attempted to show that even though both orders are found throughout the Philippines, in languages that show both orders, it is the older $\langle u m\rangle\langle i n\rangle$ order that is found in frozen forms. Now, if so many languages have switched the order affixation from $\langle u m\rangle\langle i n\rangle$ to $\langle i n\rangle\langle u m\rangle$, apparently independently, is it possible to determine what the motivation could have been for the change? In Section 2 of this paper, the problem of characterizing Tagalog voice and aspect affixes as either derivational or inflectional was discussed. It was noted that both affix sets 
have been reconstructed as derivational, noun deriving affixes in ProtoAustronesian, and that voice affixation, for the reasons given above, is probably still derivational not only in Tagalog, but in all Philippine languages. It may be, however, that as $\langle$ in $\rangle$ has become more and more productive as an aspect affix on verbs, it has moved from being a derivational affix to an inflectional affix, and would therefore require that verbs first be derived with voice-marking affixes such as $\langle u m\rangle$ and $P i$ - before being inflected with $\langle$ in $\rangle$.

4.3 The third question that must be answered in order to reconstruct the PEF aspect paradigm is whether the reduplication that marked continuative verb forms was CVC-, as in Ilokano, or CV:- as in Tagalog. The Cordilleran languages generally agree with Ilokano in showing CVC-, whereas Central Philippine languages agree with Tagalog in having either CV:- or CV- without length. There are two considerations that suggest that it is Ilokano that directly reflects the PEF reduplicative forms. The first is that it is necessary to reconstruct for $\mathrm{PEF}{ }^{*} \mathrm{CV}$ - reduplication to mark noun plurality. This form is reflected widely throughout the family. Ilokano and other Cordilleran languages distinguish between this form and CVC- as the marker of continuative verb forms. It seems more likely that languages that do not distinguish the two reduplicative patterns have collapsed them, than that those languages that do distinguish the patterns have innovated a distinctive pattern. The second is that Ilokano and other Cordilleran languages typically have a phonologically conditioned variant (CV:- in Ilokano), occurring with verbs that have a medial glottal stop, since the $\mathrm{PC}$ sequence that would result from the CVC-reduplication of these forms is disallowed in these languages. In Ilokano, the glottal stop is deleted with compensatory vowel lengthening. Other languages have developed different strategies to cope with such disallowed sequences. Bontok, for example, assimilates the glottal stop to the following consonant, so that CVC- + dáPit 'sew' becomes daddáPit 'sewing'. This pattern is generalized in Bontok (with some modifications) to verb stems that have medial glides and liquids, even though consonant clusters with initial glides and liquids are not otherwise disallowed in the language. In Tagalog, as in other Central Philippine languages that also show CV:-, consonant clusters with initial glottal stops are also disallowed. It is probable that the same process of loss of glottal stop in this position with compensatory vowel lengthening and subsequent generalization to all consonants in this position has brought about the change to CV:- in these languages.

Table 4 presents the aspect paradigm for Proto-Extra Formosan $*\langle$ um $\rangle$ and *?i- verbs. The verb roots that appear in the chart are not 
TABLE 4. PROTO-EXTRA FORMOSAN ASPECT PARADIGMS

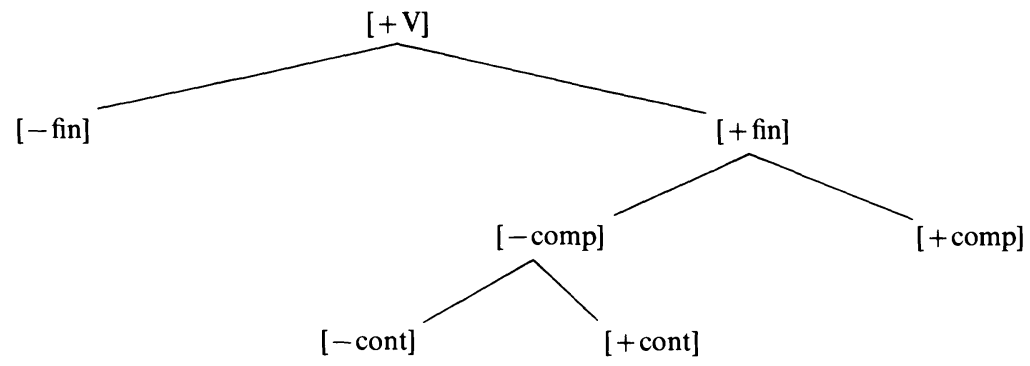
(a) tumakdér
tumakdér
tumaktakdér
tuminakdér 'to stand'
'stands'
'is standing'
'stood'
(e) Pibeléng
'to throw out'
Pibeléng
'throws out'
Pibelbeléng
'is throwing out'
Pibineléng
'threw out'

\section{TABLE 5. PRE-ILOKANO ASPECT PARADIGMS, STAGE 1}

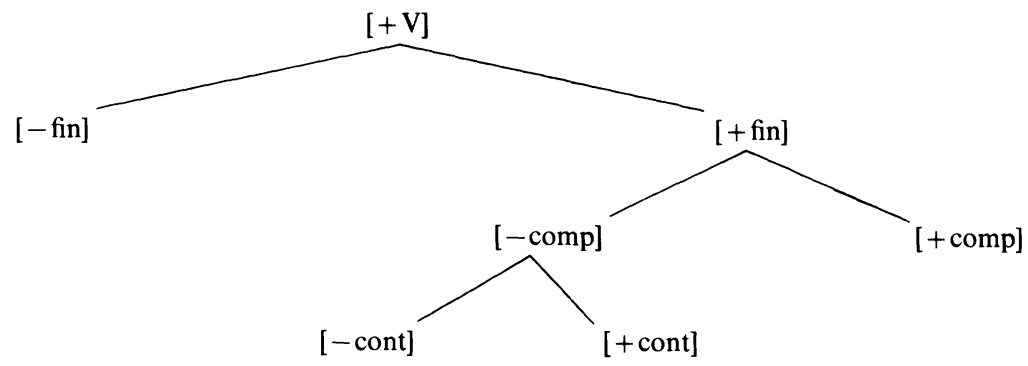
(a) tumakdér
tumakdér
tumaktakdér
tinumakdér
'to stand'
'is standing'
'stood'
(e) Pibeléng
'to throw out'
Pibeléng
'throws out'
Pibelbeléng
'is throwing out'
Pinibeléng
'threw out'

necessarily PEF reconstructions. They are pre-Ilokano forms that are used in the following section to demonstrate the development of the system into modern Ilokano.

\section{DEVELOPMENT OF THE ILOKANO ASPECT SYSTEM. Given} the Proto-Extra Formosan aspect system described in the previous section, only two stages need be postulated to account for the development of the modern Ilokano aspect system. The first was an affix-order change by which focus affixation preceded, rather than followed, the infixation of the $\langle$ in $\rangle$ completive aspect marker. The results of this change are presented in Table 5. 
TABLE 6. MODERN ILOKANO ASPECT PARADIGMS, STAGE 2

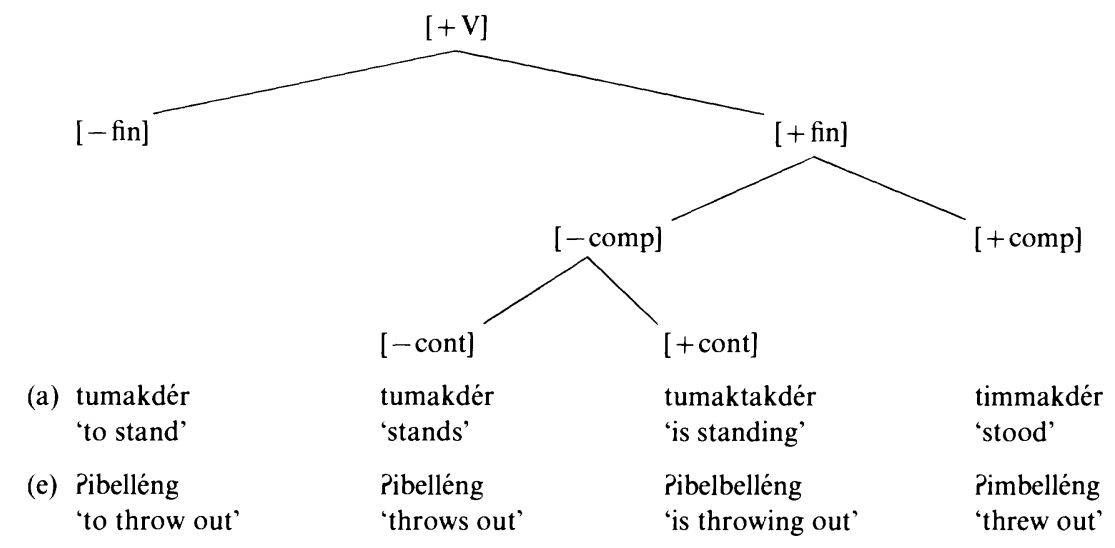

Stage 1. Affix order change.
a. $\langle u m-i n\rangle$ became $\langle i n-u m\rangle$
b. $P i-\langle i n\rangle$ became $P\langle i n\rangle i-$

The second stage brought about various phonological changes that were the result of the affix-order switch of the first stage. Vowel syncopation and nasal assimilation as described below produced the forms given in Table 6. The gemination rule described below is not pertinent to the development of the aspect system, but is included to account for the difference is root forms between the pre-Ilokano and modern Ilokano stages of tables 5 and 6 . This change could have taken place prior to the switch in affix order. One other phonological change took place, resulting in the change of CVC- to CV:- when the final consonant of the reduplicative pattern was glottal stop, as described above in Section 3 (see examples 7 and 8). This change was the result of a general loss of glottal stop in preconsonantal position in Ilokano, with associated compensatory vowel-lengthening, and was not limited to reduplicative prefixes with final glottal stop. It may have preceded or followed the switch in affix order.

Stage 2. Phonological changes.

a. Vowel loss. An affix vowel immediately following $\langle i n\rangle$ was lost.

$\begin{array}{ll}\langle\text { in-um }\rangle & \text { became }\langle\text { in- } m\rangle \\ P\langle\text { in }\rangle i- & \text { became } P\langle\text { in }\rangle-\end{array}$


TABLE 7. PROTO-EXTRA FORMOSAN ASPECT PARADIGMS

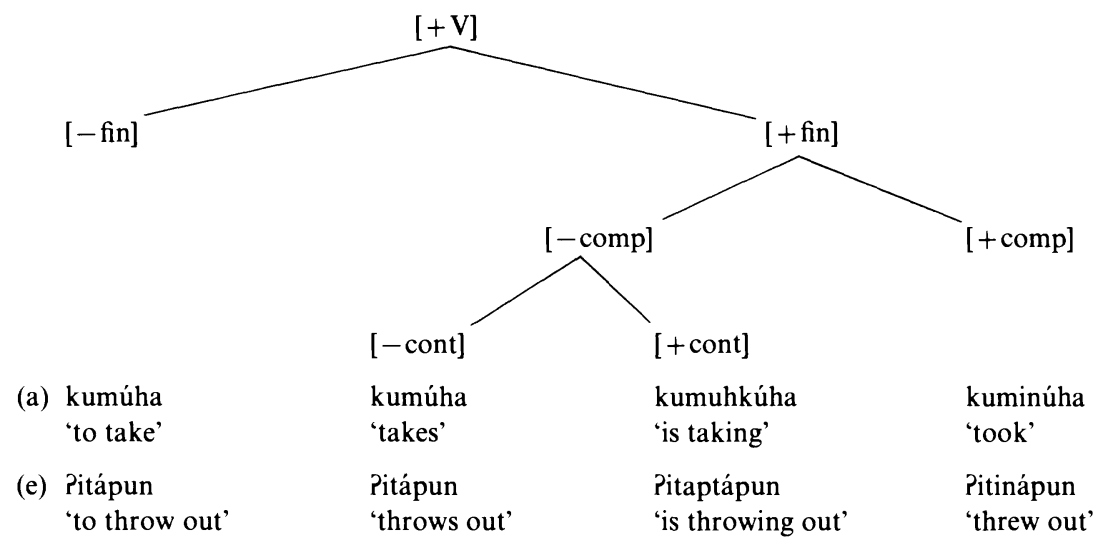

b. Assimilation. The nasal of $\langle$ in $\rangle$ was assimilated to the point of articulation of an adjacent consonant.

$\langle$ in- $m\rangle$ became $\langle$ im- $m\rangle$

$P\langle$ in $\rangle$ - became $P\langle$ im $\rangle$ - before labials

c. Gemination. Medial root consonants following *e were geminated. beleng became belleng

6. DEVELOPMENT OF THE TAGALOG ASPECT SYSTEM. The development of the Tagalog aspect system was considerably more complex than that described above for Ilokano, involving not only several phonological changes but also a complete restructuring of the system itself. As a starting point to describe these changes, Table 4 is repeated here as Table 7, but with pre-Tagalog verb roots inserted.

6.1 Stage 1. The phonological changes that apparently resulted in the restructuring of the Tagalog system must have occurred at an early stage in the development of the Central Philippine languages, since the Tagalog aspect system is typical of the Central Philippine languages (see Section 4.1 above). Vowel syncopation and assimilation occurred first, as described below and illustrated in Table 8 . These changes resulted in geminate nasal clusters in the completive aspect form of $\langle u m\rangle$ verbs. Although this stage is not attested in any Central Philippine language, identical changes have brought about the forms found in other languages of the Philippines, such as Kalinga (see example 19a). 
Stage 1. Phonological changes.

a. Vowel loss. The vowel of $\langle i n\rangle$ was lost following $\langle u m\rangle$. $\langle u m$-in $\rangle$ became $\langle u m-n\rangle$

b. Assimilation. The nasal of $\langle$ in $\rangle$ assimilated to an adjacent consonant.

$\langle u m-n\rangle$ became $\langle u m-m\rangle$

6.2 Stage 2. The major phonological change that took place in the second stage (illustrated in Table 9) was the simplification of geminate consonant

TABLE 8. PRE-TAgalog ASPECT PARADigMS, STAGE 1

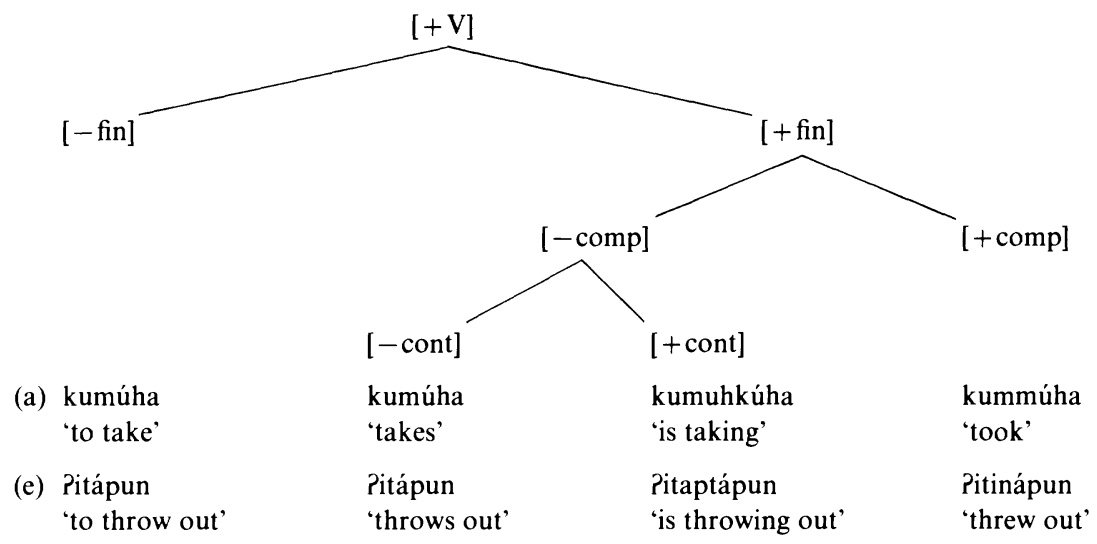

TABLE 9. PRE-TAGALOG ASPECT PARADIGMS, STAGE 2

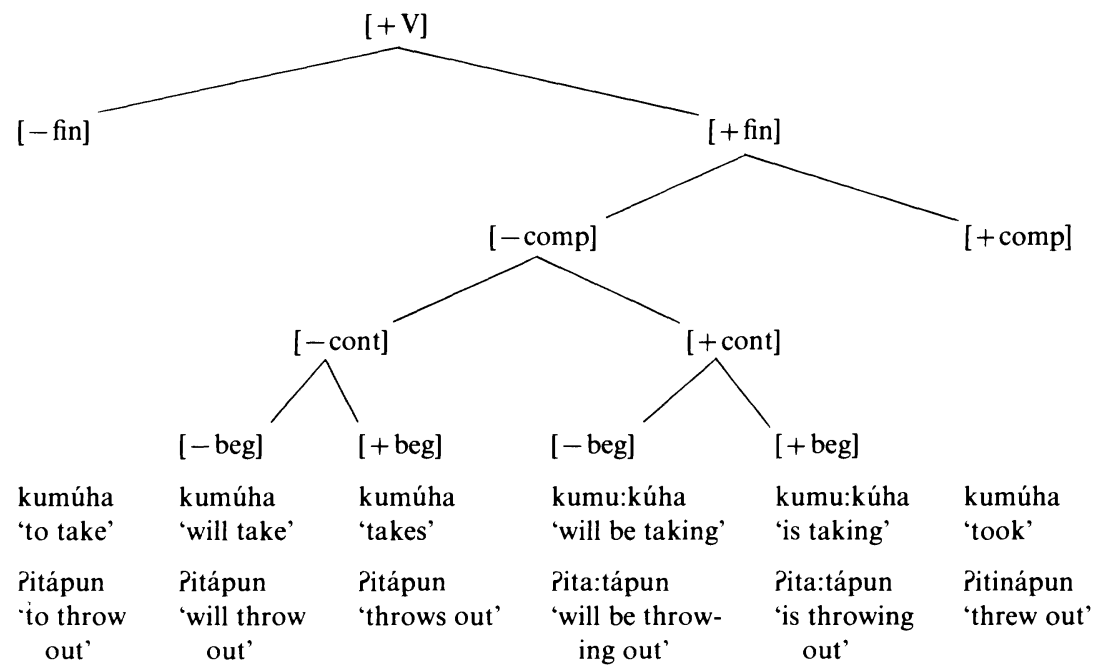


clusters. No instances of geminate consonants are presently found in Central Philippine languages, except for those resulting from prefixation as described for Tagbanwa (example 21).

21. Aborlan Tagbanwa (Hussey 1965:8-9) "No sequences of two identical consonants were found in the data apart from those formed by prefixation of a stem."

mag-gurgur 'one will weed',
mag-gated

Loss of gemination must have resulted in considerable formal ambiguity. The nonfinite, noncontinuative, and completive forms would all have been formally identical. There were, in addition, other areas of formal ambiguity. No distinction was made in the verb between future and present forms. Both the $[-$ cont $]$ and $[+$ cont $]$ forms could be interpreted as either [-begun], that is, future, or [+ begun], that is, present. It is probable, though, that such distinctions would have been marked in other ways, for example with a postclitic (22), or an "auxiliary" verb (23), as is found in Northern Philippine languages that have not restructured their aspect systems.

22. Ilokano:

uminom 'drinks'

uminom to 'will drink'

23. Bontok:

omey 'goes'

as omey 'will go'

One other phonological change that must have taken place fairly early in the history of the Central Philippine group, since it is shared by all the languages, is the change of CVC- to CV:-. As in Ilokano, it was probably the result of the loss of glottal stop in preconsonantal position, with compensatory vowel lengthening, but unlike Ilokano, the change was generalized to affect all consonants in this position.

Stage 2. Phonological changes.

a. Loss of consonant gemination

b. CVC- became CV:-

The phonological changes that resulted in the loss of $\langle$ in $\rangle$ as part of the completive aspect form of $\langle u m\rangle$ verbs in Tagalog may also have taken place early in the development of other Central Philippine languages 
TABLE 10. PRE-TAGALOG ASPECT PARADIGMS, STAGE 3a: 〈um〉 verbs

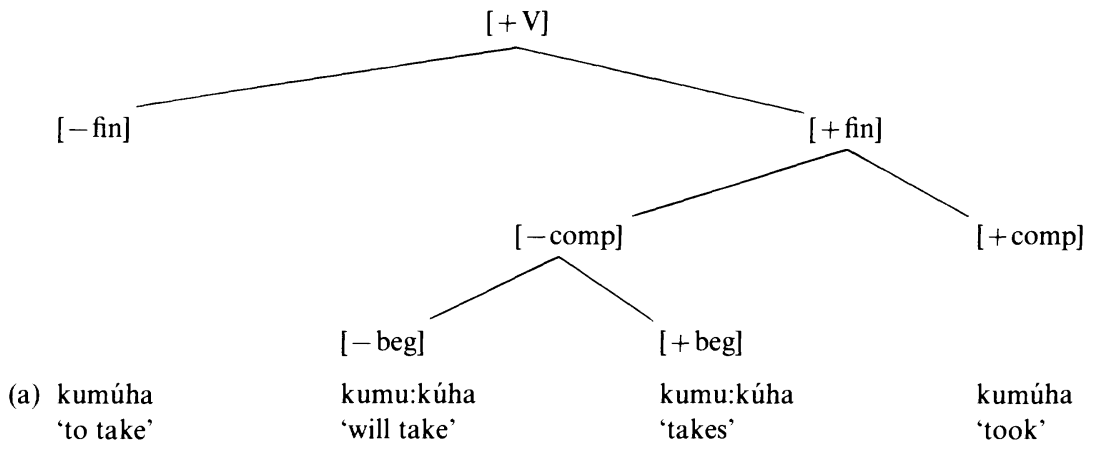

such as Cebuano, which are like Tagalog in marking completive aspect with $\langle u m\rangle$ alone (or a subsequent development of $\langle u m\rangle$, such as Cebuano $m u$-). However there are a number of Central Philippine dialects that still reflect the full form $\langle u m i n\rangle$, such as Sorsogon, or that have apparently switched the order of affixation, such as Samar-Leyte and Waray (in which the form $\langle$ inm $\rangle$ reflects an earlier $\langle$ inum $\rangle$ ), and Hiligaynon (in which the form 〈imn 〉 shows a metathesis of the bilabial and alveolar nasals, a process common throughout the Bisayan dialects) (Zorc 1977:58, 182, $138,290)$. The presence of $\langle$ in $\rangle$ in these forms makes it clear that the changes being described here for Tagalog must have taken place after the initial dispersal of Central Philippine languages.

6.31 Stage 3a. The first step in the restructuring of the system would have affected only $\langle u m\rangle$ verbs. Resolving the ambiguity between the [+ comp] and $[-$ cont $]$ forms of these verbs was accomplished by eliminating the distinction between [ $[-$ cont] and [ + cont $]$ in favor of the $[+$ cont $]$ forms. This would still however have left ambiguity between the present $[+$ begun] and future [-begun] forms, as seen in Table 10. Completive verbs now fall into two classes, those marked morphologically by $\left\langle u m_{2}\right\rangle$, and those by $\langle i n\rangle$. The affix $\left\langle u m_{1}\right\rangle$ marks nonfinite verbs, and with reduplication, noncompleted finite verbs.

6.32 Stage 3b. The second step in the restructuring of the system resulted from the association of $\left\langle u m_{2}\right\rangle$ with completed aspect, and its presence with reduplication in [+ begun] forms. This allowed the morphologization, and thus the disambiguation, of the features [ \pm begun]. The affix $\left\langle u m_{2}\right\rangle$ became the marker of [ + begun], and its absence the marker of [ - begun] (see Table 11).

6.33 Stage 3c. With $\left\langle u m_{2}\right\rangle$ now functioning as the marker of [+ begun], analogical pressure must soon have resulted in its corresponding mor- 
TABLE 11. PRE-TAGALOG ASPECT PARADIGMS, STAGE 3b: 〈um 〉 verbs

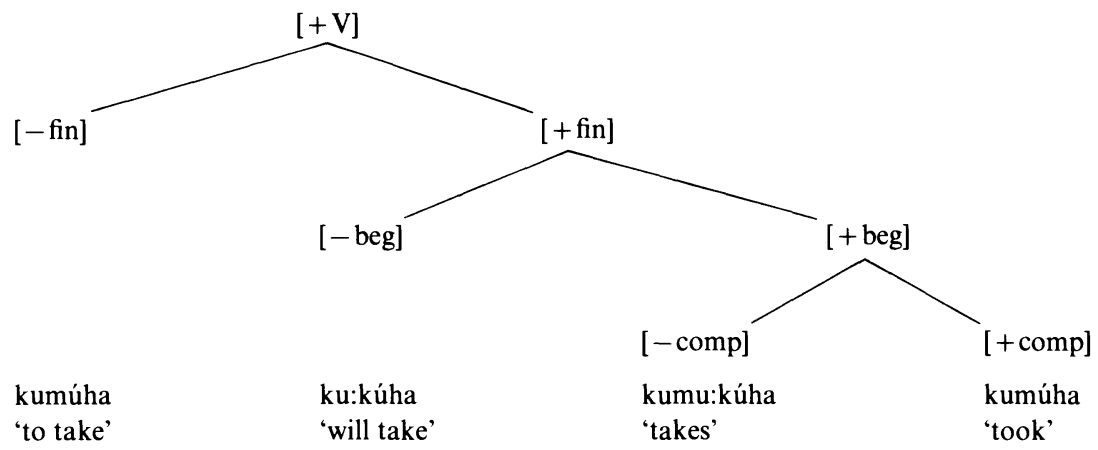

TABLE 12. TAGALOG ASPECT PARADIGMS, STAGE 3c

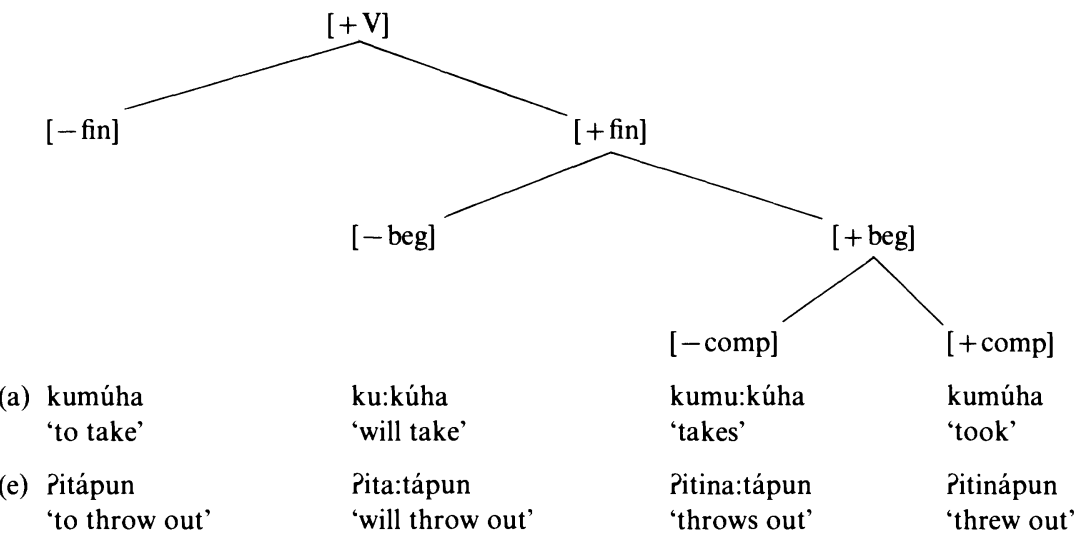

pheme $\langle$ in $\rangle$ beginning to function in the same way. The system for $\langle$ in $\rangle$ verbs was restructured to match that of the $\langle u m\rangle$ verbs, and the modern Tagalog system came into being (Table 12).

6.4 The changes that have been discussed here, which resulted in the modern Tagalog aspect system, can be plausibly characterized as abductive innovations, in the sense described by Anderson (1973). Anderson's concern was primarily with providing explanations for diachronic phonological changes. However, abductive inference is just as applicable as an explanation for innovations that have taken place in morphology and syntax as it is for those that have occurred in phonology (see Starosta $1991 b$, for a discussion of abductive change in syntax). As described by Anderson, abductive inference occurs in the process of a child's formulation of his/her grammar. "Abduction proceeds from an observed result, 
invokes a law, and infers that something may be the case" (Anderson 1972:775). The "observed result" is the output of the grammars of the adults who provide language input to the child. The "laws" that are invoked are the universal principles of syntactic organization that children are presumably born with. The inferences that children make are the morphological and syntactic rules that they develop to account for the input. Where ambiguity exists in the language of the older generation, the stage is set (Anderson's [1972: 789] "necessary condition") for abductive innovative change. We have seen how loss of gemination in Tagalog resulted in considerable formal ambiguity in the language. Children, faced with providing a syntactic explanation as they developed their own internalized grammars for the fuzzy data that they were receiving, restructured the aspectual system, favoring the use of some forms, eliminating the use of others, and redefining the functions of some morphemes. The sum of all of these abductive innovations eventually resulted in an aspectual system considerably different from the one that must be reconstructed for the language of their PEF ancestors.

\section{NOTES}

1. This paper was presented to the 6th International Conference on Austronesian Linguistics, Honolulu, May 1991. An early version was presented to a meeting of the Linguistics Society of the Philippines, Manila, March 1990. I wish to thank Byron Bender and Stanley Starosta for reading and commenting on various versions of this paper. I also wish to acknowledge support from the Social Science Research Institute at the University of Hawaii.

2. Gonzalez (1972:72) notes, "In actual usage the number of semantic derivational units attached to the root is usually only one or two, three at the most. Still these monstrous accretions are possible: ... makápakipagpakápabáyu 'to be able to participate [with some group] in exerting [oneself] in causing [somebody] to make [something] new'." Hidalgo and Hidalgo (1971:124) cite forms such as kapakapachipangadádaw "has just been able to participate in showing affection'. Vanoverbergh (1955:225-233) cites around seven hundred possible forms for the verb surat 'write', the great majority of which can also occur with the root reduplicated in at least two different ways.

3. McKaughan (1959) considers Maranao to have four inflectional categories: voice, mode, aspect, and tense.

4. Their derivational characteristics are a result of their historical origin as nounderiving processes in Proto-Austronesian (Starosta, Pawley, and Reid 1982).

5. It should be noted that although these features are actually aspectual, they have often been described in the literature as though they were features of tense, because the distinctions often carry over in translation as differences in tense. In the sources that are cited in this paper, terms such as "past tense" (for completive aspect) and "future tense" (for action not begun) are frequently used, and it is for this reason that the label "tense-aspect" instead of simply "aspect" commonly appears in descriptions of Philippine languages. Wolff (1973) refers to these affixes as "tense-mode." 
6. Ilokano distinguishes the morphological marking of beneficiary from instrumental voice (Ilokano $i$ - -an, $i$-; Tagalog $i$-), and temporal from locative voice (Ilokano panag-, -an; Tagalog -an). (See De Guzman 1978:139.)

7. The use of this label for the parent of all of the Austronesian languages outside of Taiwan avoids a commitment to the validity of a Malayo-Polynesian, which contains all the Philippine languages as a single subgroup within its western branch.

8. Ramos (1971:23) characterizes the same forms as contemplated (future), incompleted (progressive), and completed (past). Similarly Llamzon (1976:88) refers to the contemplated aspect as "future aspect."

9. There is a wide range of analyses and associated terminology connected with voice distinctions in Philippine languages (see Constantino 1971, Kerr 1965, Kess 1967, McKaughan 1958, Reid 1966). I am more concerned in this paper with the development of the verb forms than with their syntactic functions, and so will not attempt any discussion of these analyses. The terminology used here is simply a set of convenient labels with which to refer to verb forms that have the same phonological characteristics, some of which have widely varying syntactic functions in the language.

10. De Guzman (1978:150) analyzes the mag- prefix as a combination of a derivational prefix pag-plus an $m$ - inflectional prefix, an analysis which neatly captures the historical development of the prefix. Wolff $(1973: 74,84)$ also notes the similarity in form and function of $\langle u m\rangle$ and mag- and considers mag- to be the surface form of a deep structure pag- $+\langle u m\rangle$.

11. For a discussion of the historical development of these affixes and the focus system which they mark, see Pawley and Reid 1979; Starosta, Pawley, and Reid 1982; and, from a different point of view, Wolff 1973.

12. Pittman (1966) discusses the differences represented by the choice between Tagalog $\langle u m\rangle$ and mag-. He notes that with identical verb stems they may be either reflexive or nonreflexive, causative or noncausative, centripetal or noncentripetal, dual (and reciprocal) or nondual (and nonreciprocal), repetitive or nonrepetitive, or 'having intrinsic color change' or 'external color application'.

13. From the point of view of the now widely accepted ergative character of Tagalog syntax (Starosta 1988), verbs with "agentive voice" affixation that have two nominal arguments are antipassive and therefore intransitive.

14. For a discussion of the problems associated with an adequate characterization of reduplication in Tagalog, see Carrier 1979 and Carrier-Duncan 1984.

15. If, as Starosta (1991a) claims, any rule which refers to a word-internal morphological boundary is wrong, then having to refer to the first vowel of a root in order to characterize Tagalog infixation for completed aspect is evidence that aspect-marking in Tagalog cannot be inflectional.

16. Only enough of the voice-affix system is shown here to illustrate the possible affix combinations.

17. See, for example, Vanoverbergh 1955:222.

18. In these and subsequent examples, either commonly used orthographic conventions or the orthography of the source is used.

19. Harmon (1977:105) states that Kagayanen Manobo has two aspects, [-begun] encompassing contemplated actions and commands, and [+ begun] encompassing those actions which have begun and may or may not be completed. The only data given, however, are all translated perfectively. If in fact these are the relevant features for Kagayanen verbs, it is probably the result of areal influence, in that this language has been heavily influenced by languages in the Central Philippines which have the same aspect system as Tagalog. 
"Kagayanen is a Manobo language with a heavy overlay of Bisayan vocabulary" (Harmon 1977: vii).

20. Unreal aspect $m$ - has a zero variant on "modeless" verbs (Morey 1964:70).

21. That Palawano has changed as a result of areal influence from a Central Philippine language, rather than sharing in the innovations that probably brought about this type of system, is clear from Revel-MacDonald's (1979) description. In the non-agentive voices (example 1 below), the aspect system is structurally identical to that described above for Tagalog, with perfect, present progressive, future, and imperative (i.e., basic) forms. The affix $\langle$ in $\rangle$ is used to distinguish the begun (perfect and present progressive) from the notbegun (future and imperative) forms. However the agentive voice forms (examples 2 and 3 below) have only partly changed. Verbs that take the $\langle u m\rangle$ affix are like the non-agentive voice forms in terms of the structure of the system, but they restrict $\langle i n\rangle$ to the perfective form. Verbs that are derived with pag- distinguish only perfective, present progressive, and future forms, with $\langle$ in $\rangle$ being used only in the perfective forms, and with reduplication serving to mark the progressive forms, similar to what has been described for Ilokano.

1. Tense-aspect of $i$-verbs (non-agentive)

$\begin{array}{ll}\text { ilinamuq } & \text { 'cooked (rice) with X' } \\ \text { ilinalamuq } & \text { 'is cooking (rice) with X' } \\ \text { ilalamuq } & \text { 'will cook (rice) with X' } \\ \text { ilamuq } & \text { 'cook (rice) with X!' }\end{array}$

2. Tense-aspect of verbs with $\langle u m\rangle$

$\begin{array}{ll}\text { suminurung } & \text { 'went' } \\ \text { sumusurung } & \text { 'is, was going' } \\ \text { susurung } & \text { 'will go' } \\ \text { sumurung } & \text { 'go!' }\end{array}$

3. Tense-aspect of pag-derived verbs (agentive)

nägdarak 'ran'

mägdadarak 'is running'

mägdarak 'will run; run!'

Green (1979) reports that Tagbanwa in Palawan is apparently undergoing a shift from "incomplete versus complete" aspect marking on its verbs to "begun versus not-yet-begun" action. He suggests that "it may be an attempt by the speakers, ... to harmonize Tagbanwa with Tagalog, the lingua franca of Palawan and a language in which most of the speakers of Tagbanwa are functionally fluent" (Green 1979:85). The morphological devices that Tagbanwa uses to distinguish the begun from the not-yet-begun aspect do not include a reflex of * $\langle$ in $\rangle$. In Tagbanwa this affix is restricted to the completed action aspect.

22. According to Pallesen (1977), Sama traders from the Sulu archipelago in the south of the Philippines took back Bisayan-speaking wives from the Butuan area of Northern Mindanao some 700 years ago. The language that has developed as a result is Tausug.

23. That is, stems that originally had initial glottal stops.

24. Contrary to Wolff (1973:74), who reconstructs for Proto-Austronesian *-inum- "past independent active affix." Formosan languages generally reflect 
*〈umin〉, e.g. Atayal mnlax "gave up" (alax + mn-) (Wolff 1973), although Tsouic shows the reverse order: $t$-in-əm-ani-úlar ' 'maltreated' (Tsuchida 1976:43).

25. In Shetler's (1976:43) terms, "When Past Tense -in- cooccurs with Subject Focus - $u m$ - in a stem which begins with a CV syllable, the $i$ of Tense is reduced; the $n$ of Tense and $u$ of Focus metathesize ... and the $n$ of Tense assimilates to $m . "$

26. From an earlier ${ }^{*} \mathrm{p}\langle\mathrm{um}\rangle\langle$ in $\rangle \mathrm{a}$ - sequence. In Proto-Extra Formosan (if not in Proto-Austronesian), when $\langle\mathrm{um}\rangle$ was infixed into words with initial bilabial stops, the first two segments of the infixed word were deleted. This rule is still present in languages such as Tagbanwa, Palawano, some Manobo languages, and Blaan (see also Wolff 1973:84). Frozen forms such as matay die (from $p\langle u m\rangle$ atay) occur in various other languages, such as Tagalog.

\section{REFERENCES}

Allen, Lawrence A. 1977. Reduplication and cyclical rule ordering in Kankanaey morphophonemics. Studies in Philippine Linguistics 1(2):280-295.

Anderson, Henning. 1973. Abductive and deductive change. Language 49:765793.

Antworth, Evan L. 1979. A grammatical sketch of Botolan Sambal. Special Monograph Issue Number 8. Philippine Journal of Linguistics.

Bender, Byron W. 1988. Morphology Course Notes. Typescript.

Benton, Richard A. 1971. Pangasinan reference grammar. PALI Language texts: Philippines. Honolulu: University of Hawaii Press.

Brandes, Carlos and Otto Scheerer. 1927-28. On sandhi in the Ibanag language. The Archive, Paper Number 6. Manila: University of the Philippines.

Carrier, Jill. 1979. The interaction of morphological and phonological rules in Tagalog. Ph.D. dissertation, MIT.

Carrier-Duncan, Jill. 1984. Some problems with prosodic accounts of reduplication. In Language Sound Structure, ed. by Mark Aranoff and Richard T. Oehrle, pp. 260-286. Cambridge: MIT Press.

Constantino, Ernesto. 1971. Ilokano reference grammar. PALI Language Texts: Philippines. Honolulu: University of Hawaii Press.

De Guzman, Videa P. 1978. Syntactic derivation of Tagalog verbs. Oceanic Linguistics Special Publication No. 16. Honolulu: University of Hawaii Press.

- 1991. Inflectional morphology in the lexicon: Evidence from Tagalog. Oceanic Linguistics 30:33-48.

Du Bois, Carl. n.d. Sarangani Manobo: An introductory guide. Unpublished typescript. Nasuli, Malaybalay, Bukidnon: Summer Institute of Linguistics.

Gieser, C. Richard. 1963. A grammatical sketch of Kalinga. Mimeo. Nasuli, Malaybalay, Bukidnon: Summer Institute of Linguistics.

Gonzalez, Andrew, F. S. C. 1972. Pampangan: Outline of a generative semantic description. Manila: Research Council, De La Salle College.

Green, Peter. 1979. Co-existent aspect-marking phenomena in Tagbanwa of Palawan Island. Pacific Linguistics A-50, Papers in Philippine Linguistics No. 9. Canberra: The Australian National University.

Harmon, Carol. 1977. Kagayanen and the Manobo subfamily of Philippine languages. Ph.D. dissertation, University of Hawaii. 
Hidalgo, Cesar A., and Araceli C. Hidalgo. 1971. A tagmemic grammar of Ivatan. Manila: Linguistic Society of the Philippines.

Hussey, Stewart. 1965. Aborlan Tagbanwa: Verbal system and related topics. M. A. thesis, Hartford Seminary Foundation.

Kerr, Harland B. 1965. The case-marking and classifying function of Cotabato Manobo voice affixes. Oceanic Linguistics 4: 15-47.

Kess, Joseph F. 1967. Syntactic features of Tagalog verbs. Ph.D. dissertation, University of Hawaii.

Larson, Virginia. 1986. Ivatan texts. Manila: Summer Institute of Linguistics.

Llamzon, Teodoro A. 1976. Modern Tagalog: A functional-structural description. The Hague: Mouton.

Li, Paul Jen-Kuei. 1973. Rukai structure. Institute of History and Philology Special Publication Number 64. Nankang, Taipei: Academia Sinica.

Miller, Jeanne. 1973. Semantic structure of Mamanwa verbs. Linguistics 110:7481.

Miller, Jeanne, and Helen Miller. 1976. Mamanwa grammar. Language Data, Asian-Pacific Series, Number 8. Huntington Beach, California: Summer Institute of Linguistics.

McKaughan, Howard P. 1958. The inflection and syntax of Maranao verbs. Manila: Institute of National Language.

Morey, Virginia. 1964. Distributional restrictions on co-occurrence of aspect and focus morphemes in Ata verbs. Oceanic Linguistics 31:69-86.

Otanes, Fe T. 1966. A contrastive analysis of English and Tagalog verb complementation. Ph. D. dissertation, University of California, Los Angeles.

- 1970. Some transformation rules for noun derivation in Tagalog. Philippine Journal of Linguistics 1:33-73.

Pallesen, A. Kemp. 1977. Culture contact and language convergence. Ph.D. dissertation, University of California, Berkeley.

Pawley, Andrew K., and Lawrence A. Reid. 1979. The evolution of transitive constructions in Austronesian. In Austronesian Studies: Papers from the Second Eastern Conference on Austronesian Languages, ed. by Paz B. Naylor, pp. 103-130. Ann Arbor: Center for South and Southeast Asian Studies, University of Michigan.

Pittman, Richard. 1966. Tagalog -um- and mag-, an interim report. Linguistic Circle of Canberra Publications A-8. Canberra: The Australian National University.

Ramos, Teresita V. 1971. Tagalog structures. PALI Language Texts: Philippines. Honolulu: University of Hawaii Press.

Reid, Lawrence A. 1966. An Ivatan syntax. Oceanic Linguistics Special Publication No. 2. Honolulu: University of Hawaii Press.

. 1978. Yogad and Itawis Fieldnotes.

1987. The early switch hypothesis: Linguistic evidence for contact between Negritos and Austronesians. Man and Culture in Oceania 3, Special Issue: $41-59$.

- 1988. The Alta languages of the Philippines. Paper presented to the Fifth International Conference on Austronesian Languages, Auckland, New Zealand.

Revel-Macdonald, Nicole. 1979. Le Palawan (Philippines). Langues et Civilisations de l'Asie du Sud-Est et du Monde Insulindien Monograph \# 4. Paris: Centre National de la Recherche Scientifique.

Schachter, Paul, and Fe T. Otanes. 1972. Tagalog reference grammar. Berkeley, Los Angeles, and London: University of California Press. 
Shand, Jean. 1964. Categories and markers of tense, focus, and mode in Ilianen Manobo. Oceanic Linguistics 3:58-68.

Shetler, Joanne. 1976. Notes on Balangao grammar. Language Data, Asian-Pacific Series, Number 9. Huntington Beach, California: Summer Institute of Linguistics.

Starosta, Stanley. 1986. Focus as recentralization. In FOCAL I: Papers from the Fourth International Conference on Austronesian Linguistics, ed. by Paul Geraghty, Lois Carrington, and S. A. Wurm, pp. 73-95. Pacific Linguistics C-93. Canberra: The Australian National University.

. 1988. The case for lexicase. London: Pinter Publishers.

1991a. No more boundaries, no more phemes. Paper presented to the Tuesday Seminar, Department of Linguistics, University of Hawaii.

$1991 b$. The great Aux cataclysm: Diachronic justification for a synchronic analysis. In Studies in Dravidian and General Linguistics: A Festschrift for Bh. Krishnamurti, ed. by B. Lakshmi Bai and B. Ramakrishna Reddy, pp. 505515. Osmania University Publications in Linguistics No. 6.

Starosta, Stanley, Andrew K. Pawley, and Lawrence A. Reid. 1982. The evolution of focus in Austronesian. In Papers from the Third International Conference on Austronesian Linguistics, vol. 2, Tracking the travellers, ed. by Amran Halim, Lois Carrington, and S. A. Wurm, pp. 145-170. Pacific Linguistics C-75. Canberra: The Australian National University.

Svelmoe, Gordon, and Thelma M. Svelmoe. 1974. Notes on Mansaka grammar. Language Data, Asian-Pacific Series, Number 6. Huntington Beach: Summer Institute of Linguistics.

Tsuchida, Shigeru. 1976. Reconstruction of Proto-Tsouic phonology. Monograph Number 5. Tokyo: Institute for the Study of Languages and Cultures of Asia and Africa.

Vanoverbergh, Morice. 1955. Iloko grammar. Baguio City: Catholic School Press.

West, Anne. 1973. The semantics of focus in Amganad Ifugao. Linguistics 110:98121.

Wolff, John U. 1973. Verbal inflection in Proto-Austronesian. In Parangal Kay Cecilio Lopez, ed. by Andrew B. Gonzalez, pp. 71-91. Philippine Journal of Linguistics Special Monograph Issue No. 4.

Zorc, R. David. 1977. The Bisayan dialects of the Philippines: Subgrouping and reconstruction. Pacific Linguistics C-44. Canberra. The Australian National University. 
http://www.jstor.org

\title{
LINKED CITATIONS \\ - Page 1 of 1 -
}

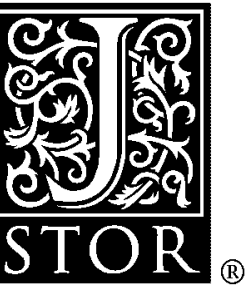

You have printed the following article:

On the Development of the Aspect System in Some Philippine Languages

Lawrence A. Reid

Oceanic Linguistics, Vol. 31, No. 1. (Summer, 1992), pp. 65-91.

Stable URL:

http://links.jstor.org/sici?sici=0029-8115\%28199222\%2931\%3A1\%3C65\%3AOTDOTA\%3E2.0.CO\%3B2-J

This article references the following linked citations. If you are trying to access articles from an off-campus location, you may be required to first logon via your library web site to access JSTOR. Please visit your library's website or contact a librarian to learn about options for remote access to JSTOR.

\section{References}

\author{
Inflectional Morphology in the Lexicon: Evidence from Tagalog \\ Videa P. De Guzman \\ Oceanic Linguistics, Vol. 30, No. 1. (Summer, 1991), pp. 33-48. \\ Stable URL: \\ http://links.jstor.org/sici?sici=0029-8115\%28199122\%2930\%3A1\%3C33\%3AIMITLE\%3E2.0.CO\%3B2-0
}

\author{
The Case-Marking and Classifying Function of Cotabato Manobo Voice Affixes \\ Harland B. Kerr \\ Oceanic Linguistics, Vol. 4, No. 1/2. (1965), pp. 15-47. \\ Stable URL: \\ http://links.jstor.org/sici?sici=0029-8115\%281965\%294\%3A1\%2F2\%3C15\%3ATCACFO\%3E2.0.CO\%3B2-L
}

\author{
Distributional Restrictions on Co-Occurrence of Aspect and Focus Morphemes in Ata Verbs \\ Virginia Morey \\ Oceanic Linguistics, Vol. 3, No. 1, Papers in Philippine Linguistics. (Summer, 1964), pp. 69-86. \\ Stable URL: \\ http://links.jstor.org/sici?sici=0029-8115\%28196422\%293\%3A1\%3C69\%3ADROCOA\%3E2.0.CO\%3B2-W
}

\section{Categories and Markers of Tense, Focus and Mode in Ilianen Manobo}

Jean Shand

Oceanic Linguistics, Vol. 3, No. 1, Papers in Philippine Linguistics. (Summer, 1964), pp. 58-68.

Stable URL:

http://links.jstor.org/sici?sici=0029-8115\%28196422\%293\%3A1\%3C58\%3ACAMOTF\%3E2.0.CO\%3B2-Y 